\title{
Pole-to-pole validation of GOME WFDOAS total ozone with groundbased data
}

\author{
M. Weber, L. N. Lamsal, M. Coldewey-Egbers, K. Bramstedt, and J. P. Burrows \\ Institute of Environmental Physics, University of Bremen, Bremen, Germany \\ Received: 10 June 2004 - Published in Atmos. Chem. Phys. Discuss.: 29 October 2004 \\ Revised: 1 March 2005 - Accepted: 8 April 2005 - Published: 7 June 2005
}

\begin{abstract}
This paper summarises the validation of GOME total ozone retrieved using the Weighting Function Differential Optical Absorption Spectroscopy (WFDOAS) algorithm Version 1.0. This algorithm has been described in detail in a companion paper by Coldewey-Egbers et al. (2005). Compared to the operational GDP (GOME Data Processor) V3, several improvements to the total ozone retrieval have been introduced that account for the varying ozone dependent contribution to rotational Raman scattering, includes a new cloud scheme, and uses the GOME measured effective albedo in the retrieval. In this paper the WFDOAS results have been compared with selected ground-based measurements from the WOUDC (World Ozone and UV Radiation Data Centre) that collects total ozone measurements from a global network of stations covering all seasons. From the global validation excellent agreement between WFDOAS and ground data was observed. The agreement lies within $\pm 1 \%$, and very little seasonal variations in the differences are found. In the polar regions and at high solar zenith angles, however, a positive bias varying between 5 and $8 \%$ is found near the polar night period. As a function of solar zenith angle as well as of the retrieved total ozone, the WFDOAS differences to ground polar data, however, show a much weaker dependence as compared to the operational GOME Data Processor Version 3 of GOME that represents a significant improvement. Very few stations carry out simultaneous measurements by Brewer and Dobson spectrometers over an extended period (three years or more). Simultaneous Brewer and Dobson measurements from Hradec Kralove, Czech Republic $\left(50.2^{\circ} \mathrm{N}, 15.8^{\circ} \mathrm{E}\right)$ and Hohenpeissenberg, Germany $\left(47.8^{\circ} \mathrm{N}, 11.0^{\circ} \mathrm{E}\right)$ covering the period 1996-1999 have been compared with our GOME results. Agreement with Brewers are generally better than with the simultaneous Dobson measurements and this may be explained by the neglect of stratospheric (ozone) temperature correction in the standard ozone retrieval from the ground.
\end{abstract}

Correspondence to: $\mathrm{M}$. Weber

(weber@uni-bremen.de)

\section{Introduction}

The GOME (Global Ozone Monitoring Experiment) on board the ERS-2 satellite is the first European experiment dedicated to global ozone measurements (Burrows et al., 1999a). It measures the back scattered radiances from 240 $790 \mathrm{~nm}$ in the nadir-viewing geometry. In the relevant region for total ozone retrieval $(320-340 \mathrm{~nm})$ the spectral resolution is about $0.17 \mathrm{~nm}$. The maximum scan width in the nadir is $960 \mathrm{~km}$ across track on the ground and global coverage is achieved within three days.

For the major parts of the orbits one across track scan sequence consists of four ground pixel types with $1.5 \mathrm{~s}$ integration time each and ground coverage is $320 \mathrm{~km}$ by $40 \mathrm{~km}$. The GOME instrument aboard ERS-2 provides regular solar irradiance and backscatter spectra starting in July 1995. In June 2003 the tape recorder for intermediate data storage failed, so that only data are transmitted to the ground when ERS-2 is in direct contact with ground stations. This limits GOME coverage to the Euro-Atlantic sector stretching from Canada to Russia.

In a companion paper (Coldewey-Egbers et al., 2005) a new total ozone retrieval algorithm has been introduced that uses the Weighting Function Differential Optical Absorption Spectroscopy (WFDOAS) approach. It introduces several new features that have not been used in prior total ozone retrievals from GOME. The variable ozone dependent contribution to the Raman scattering responsible for the filling-in of molecular absorption is properly accounted for. The use of a new cloud scheme in combination with an estimation of effective scene height lead to higher sensitivity to clouds in WFDOAS. In addition, the GOME retrieved scene albedo is included in the retrieval. It was already shown in the companion paper that these new features have improved the total ozone retrieved from GOME compared to earlier retrieval versions. This paper describes the validation of WFDOAS with ground based data on a global scale. Comparison of operational GDP (GOME Data Processor) V3 to ground data

(C) 2005 Author(s). This work is licensed under a Creative Commons License. 
are also presented to document the significant improvement achieved by WFDOAS over prior data versions.

In Sect. 2 the WFDOAS algorithm is briefly summarised. In Sect. 3 comparisons with simultaneous Brewer and Dobson measurements at Hohenpeissenberg $\left(47.8^{\circ} \mathrm{N}, 11.0^{\circ} \mathrm{E}\right)$ and Hradec Kralove $\left(50.2^{\circ} \mathrm{N}, 15.8^{\circ} \mathrm{E}\right)$ are presented and discussed. This is a very important comparison since many stations have changed or plan to change from regular Dobson to Brewer observations and a good characterisation of satellite data with respect to both spectrophotometer types is critical for long-term trend assessment from both satellite and ground time series (Staehelin et al., 2003). The next section shows comparisons with individual WOUDC stations (Sect. 4) followed by Sect. 5 summarising the statistical analysis involving all stations selected from low to mid latitudes. Most of the validation statistics at mid latitudes and in tropics rely on ground-based data between 1996 and 1999, but for selected stations the validation has been extended up to 2003 (Lauder and Hohenpeissenberg) for demonstrating the long-term stability of the GOME data. In a separate section (Sect. 6) the validation results from comparison with polar station measurements in both hemispheres from 1996 to 2003 are presented.

\section{WFDOAS algorithm}

In the WFDOAS algorithm the measured atmospheric optical depth (logarithm of the sun-normalised radiances) is approximated by a Taylor expansion around a reference intensity plus a low-order polynomial, here a cubic polynomial. The total column information is obtained only from differential trace gas structures as in case of standard DOAS and the polynomial accounts for all broadband contributions from surface albedo and aerosols.

Additional fit parameters are the Ring effect, the undersampling correction, both treated as effective absorbers similar to the approach used in standard DOAS, and a (ozone) temperature shift. Slant column fitting is also applied to the minor absorbers $\mathrm{NO}_{2}$ and $\mathrm{BrO}$. All fitting parameters are derived using a linear least squares minimisation. A large set of reference spectra has been constructed that includes nearly all possible atmospheric conditions. The radiance spectra and weighting functions were calculated as a function of total ozone including profile shape, solar zenith angle, lineof-sight, relative azimuth angle, and bottom-of-atmosphere altitude and albedo using the multiple scattering SCIATRAN radiative transfer model in the pseudo-spherical approximation (Rozanov et al., 1998).

Ozone and temperature profiles are taken from TOMS (Total Ozone Mapping Spectrometer) V7 climatology (Wellemeyer et al., 1997) which contains different profile shapes for three latitude belts (low, middle and high) as a function of total ozone column varying from $125-575 \mathrm{DU}$ in mid and high latitudes and from $225-475$ DU in low latitudes. This climatology accounts for seasonal variation and also contains typical ozone hole profiles. Solar zenith angle varies from $15^{\circ}-92^{\circ}$, line-of-sight varies from $-34.5^{\circ}$ to $+34.5^{\circ}$, and the range for the relative azimuth angle is defined by a given combination of both parameters. Altitude of the boundary in the lower atmosphere varies from 0 to $12 \mathrm{~km}$, and surface albedo from 0.02 to 0.98 . Both parameters are considered effective parameters that take into account partial cloud cover in the GOME scene.

For ozone retrieval with WFDOAS, calibrated GOME level 1 radiance and solar spectrum from the same day, a-priori values for total ozone (initial guess), effective altitude, and effective albedo are used. Effective altitude is obtained from FRESCO (Fast Retrieval Scheme for Clouds from the oxygen A-Band, Koelemeijer et al., 2001). Cloud top pressure and cloud fraction are derived from the oxygen transmittance assuming a high reflecting boundary representing the cloud top. Surface albedo is taken from minimum spectral reflectances derived from a five year GOME data record (Koelemeijer et al., 2003). The effective height is the sum of the ground altitude and the retrieved cloud top height weighted by the fractional cloud cover (ColdeweyEgbers et al., 2005).

The Lambertian Equivalent Reflectivity LER (Herman and Celarier, 1997) defines the effective albedo and is obtained from GOME sun-normalised radiances at $377.6 \mathrm{~nm}$, where variations with respect to the Ring effect are small and can be easily corrected for. A look-up-table of radiances as a function of solar zenith angle, line-of-sight, relative azimuth angle, ground altitude, and surface albedo has been pre-calculated using SCIATRAN and the LER are retrieved by finding the best match between calculated and measured TOA reflectance by inverse search in the multidimensional table.

As described in Coldewey-Egbers et al. (2005), the Raman correction to scattered intensity, the so-called Ring spectra (Solomon et al., 1987; Vountas et al., 1998), were calculated for the same atmospheric conditions including ozone variability as provided by the profile shape climatology as for the weighting functions, they are stored in look-up tables (LUT). The spectral window $326.8-335.0 \mathrm{~nm}$ is used in the ozone fitting procedure. After the iteration stops, the ghost vertical column (GVC), that is hidden below the (partial) cloud, is determined from an ozone climatology and then added to the retrieved column to obtain the final total ozone amount. The tropospheric climatological ozone is taken from the monthly and zonal mean TOMS V8 profile climatology (G. Labow, NASA GSFC, personal communication, 2001).

The following settings apply to Version 1.0 WFDOAS:

- spectral fitting window: $326.8-335.0 \mathrm{~nm}$

- fitting terms:

- ozone vertical column (weighting function)

- temperature shift (weighting function) 
- under-sampling correction

- Ring (including ozone filling-in)

- $\mathrm{NO}_{2}$

- $\mathrm{BrO}$

- a-priori ozone profile shape from total ozone dependent TOMS V7 ozone and temperature climatology (Wellemeyer et al., 1997)

- Burrows et al. (1999b) ozone cross-section shifted by $+0.017 \mathrm{~nm}$

- Fraunhofer fitting (wavelength calibration of daily solar GOME reference to Kitt Peak Fourier transform solar atlas from Kurucz et al., 1984)

- shift and squeeze of wavelength axis only for nadir radiance spectrum

- cubic polynomial subtracted in the fit

- Lambertian equivalent reflectivities $(377.6 \mathrm{~nm})$ taken as effective albedo of the scene

- cloud-top-height and cloud cover fraction derived using FRESCO (Koelemeijer et al., 2001). Effective scene height is determined from the cloud-information

- ghost vertical column correction from TOMS V8 zonal monthly mean climatology

The Fraunhofer fitting and the spectral shift of the ozone cross-section used in the radiative transfer calculation permits the limitation of wavelength adjustments (shift and squeeze) to the GOME nadir radiances. This leads to a faster retrieval on the order of five minutes per GOME orbit (about 1500 fits).

\section{GOME, Brewer, and Dobson triple comparison}

The majority of the total ozone data obtained from the ground are Dobson spectrophotometer measurements. The Dobson spectrophotometer is a double monochromator with the first prism acting as a dispersing element and the second recombining the wavelength pair on to a photomultiplier. A chopper allows the alternating measurements of the wavelength pair with a single detector (Dobson, 1931, 1968). For the standard analysis (World Meteorological Organisation - Global Atmospheric Watch (WMO-GAW), the A $(305.5 / 325.5 \mathrm{~nm})$ and $\mathrm{D}(317.6 / 339.8 \mathrm{~nm})$ wavelength pairs are used to derive total ozone (Staehelin et al., 2003). At low solar elevation the D-pair can be combined with the C-pair $311.5 / 332.4 \mathrm{~nm}$. This instrument can be operated in direct-sun and zenith sky viewing geometry. Most reliable results are obtained in direct-sun (AD pairs) with a precision of $1 \%$ using a diffuser plate. Accuracy may be lower due to systematic errors, for instance coming from uncertainties in cross-sections (Bass-Paur are used in the standard retrieval). Under cloudy conditions the error in the zenith-sky results can rise from 3\% up to 7\% (low clouds) in zenith sky measurements (R. D. Evans, NOAA, personal communication). First measurements with the Dobson instruments have been reported in the twenties (Dobson, 1931) and some of the longest time series are provided by the Dobson instruments (Staehelin, 1998).

Since the early eighties Brewer grating spectrometers have been installed at several stations (Kerr et al., 1985) and at many stations Dobson instruments have been replaced by Brewer spectrophotometers or are planned to be replaced. The Brewer is a modified Ebert type grating spectrometer which can be operated in single ("single Brewer") or double monochromator ("double Brewer") configuration. This instrument uses five wavelengths in the spectral range 306.3 and $320.1 \mathrm{~nm}$ to form several wavelength pairs for the standard ozone retrieval. Besides ozone, $\mathrm{NO}_{2}, \mathrm{SO}_{2}$, and UV-B radiation can be measured. Particularly $\mathrm{SO}_{2}$ interferes in the ozone retrieval and has to be corrected for in an urban environment. Particular advantage of the Brewer is its fully automated operation. Both direct-sun and zenith-sky measurements are possible.

In the standard retrieval, for both Brewer and Dobson instruments, the dependence of ozone cross-section on temperature is not accounted for unlike in the satellite retrieval. As discussed by Kerr (2002) atmospheric temperature corrections can be applied to Brewer retrievals, but most of the stations participating in the ground based network still rely on the standard retrieval. Based upon Bass-Paur ozone crosssection spectra (Bass and Paur, 1985) convolved to match Brewer spectral resolution, he found a $0.7 \% / 10 \mathrm{~K}$ temperature dependence for Brewer standard retrieval (Kerr et al., 1988). This number was revised to $0.94 \% / 10 \mathrm{~K}$ (Kerr, 2002). Using a different approach based upon Brewer measurements at Toronto that included ozone temperature retrieval, he found that the temperature dependence is rather negligible $(-0.05 \% / 10 \mathrm{~K})$ at standard Brewer wavelengths. For Dobson instruments the temperature dependence is $1.3 \% / 10 \mathrm{~K}$ (Komhyr et al., 1993). The temperature sensitivities cited here apply mainly to direct-sun measurements.

Only very few stations provide simultaneous measurements from Brewer and Dobson spectrometers covering an extended period. Two such stations are Hohenpeissenberg (MOHp), Germany, $47.8^{\circ} \mathrm{N}$, and Hradec Kralove, Czech Republic, $50.2^{\circ} \mathrm{N}$. Both stations in collaboration act as the Regional Dobson Calibration Centre for Europe. They have been operating a single Brewer and Dobson throughout the GOME period 1995-2003 and this data set is very valuable in evaluating the new GOME algorithm. Because of different wavelengths used in all three instruments GOME, Brewer, and Dobson results may differ.

For both stations a maximum collocation radius of $160 \mathrm{~km}$ between the centre of the GOME pixel and station location 


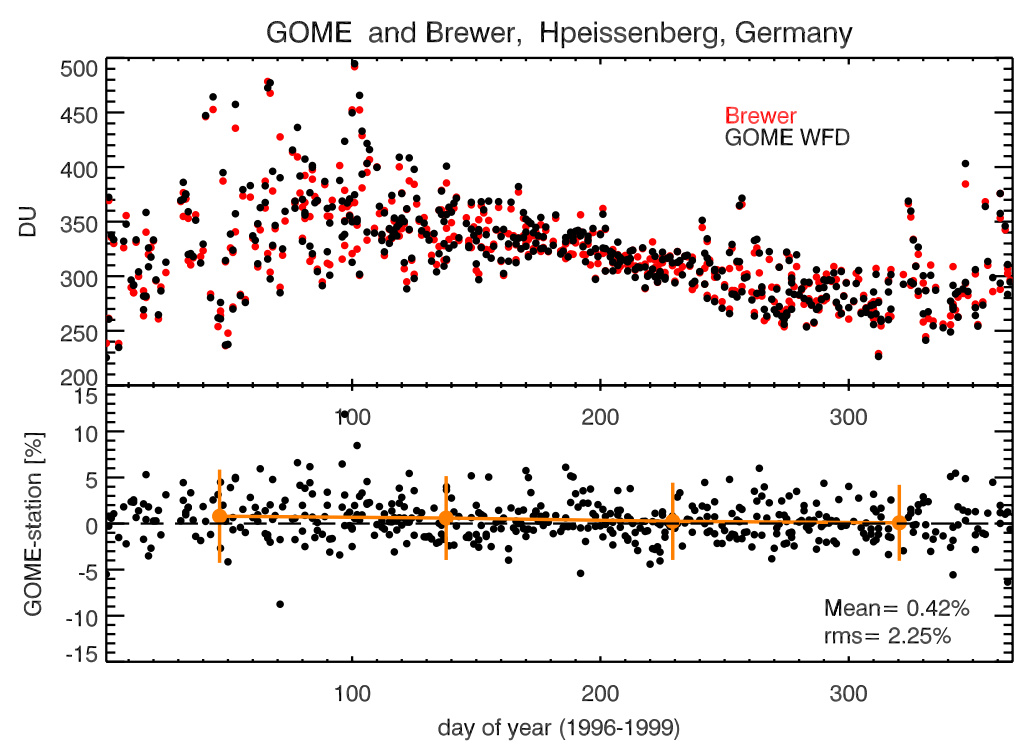

Fig. 1. Top panel: Collocated GOME WFDOAS V1.0 and Brewer total ozone from Hohenpeissenberg. Bottom panel: Differences in percent. Orange points mark the three month average in the daily differences and bars the $2 \sigma$ RMS from taking the mean.

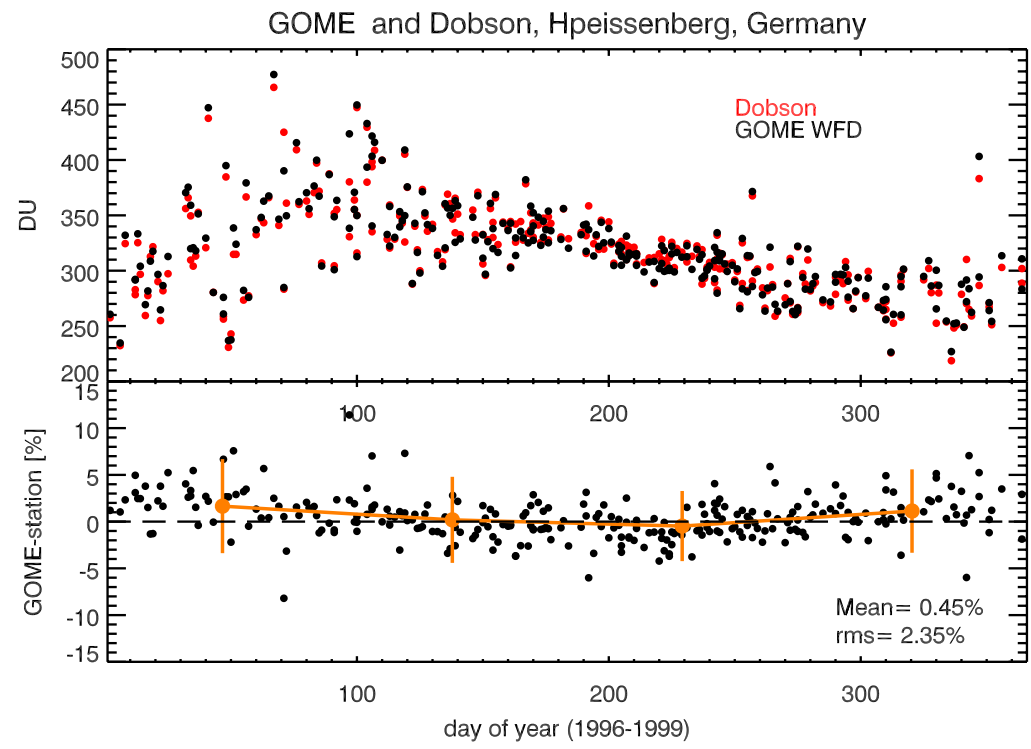

Fig. 2. Same as Fig. 1 but shown for collocated WFDOAS and Dobson measurements at Hohenpeissenberg. Only direct-sun measurements from the Dobson are shown here.

was allowed and measurements had to take place the same day. At a given day only the closest match within that radius was taken. Brewer and Dobson data were provided as daily averages. All Dobson measurements and the Hradec Kralove Brewer are limited to direct sun measurements that are considered most reliable. Hohenpeissenberg Brewer data also contain zenith-sky measurements.

Figure 1 shows the comparison between WFDOAS V1.0 and Hohenpeissenberg Brewer as a function of the day in the year (1996-1999). The top panels shows the annual cycle of total ozone with maximum ozone in spring and minimum in fall, the bottom panel the difference in percent. The WFDOAS results have a bias of $0.4 \%$ and a $\pm 0.5 \%$ variability over the annual cycle with slightly higher values in winter (JFM) than in summer/fall.

The comparison of the GOME WFDOAS V1.0 with the Dobson measurements is shown in Fig. 2. The RMS scatter in the differences are similar for both Brewer and Dobson data $(2.3 \%)$. WFDOAS exhibits a somewhat stronger seasonal cycle of $\pm 1 \%$ when compared to Dobson with a 

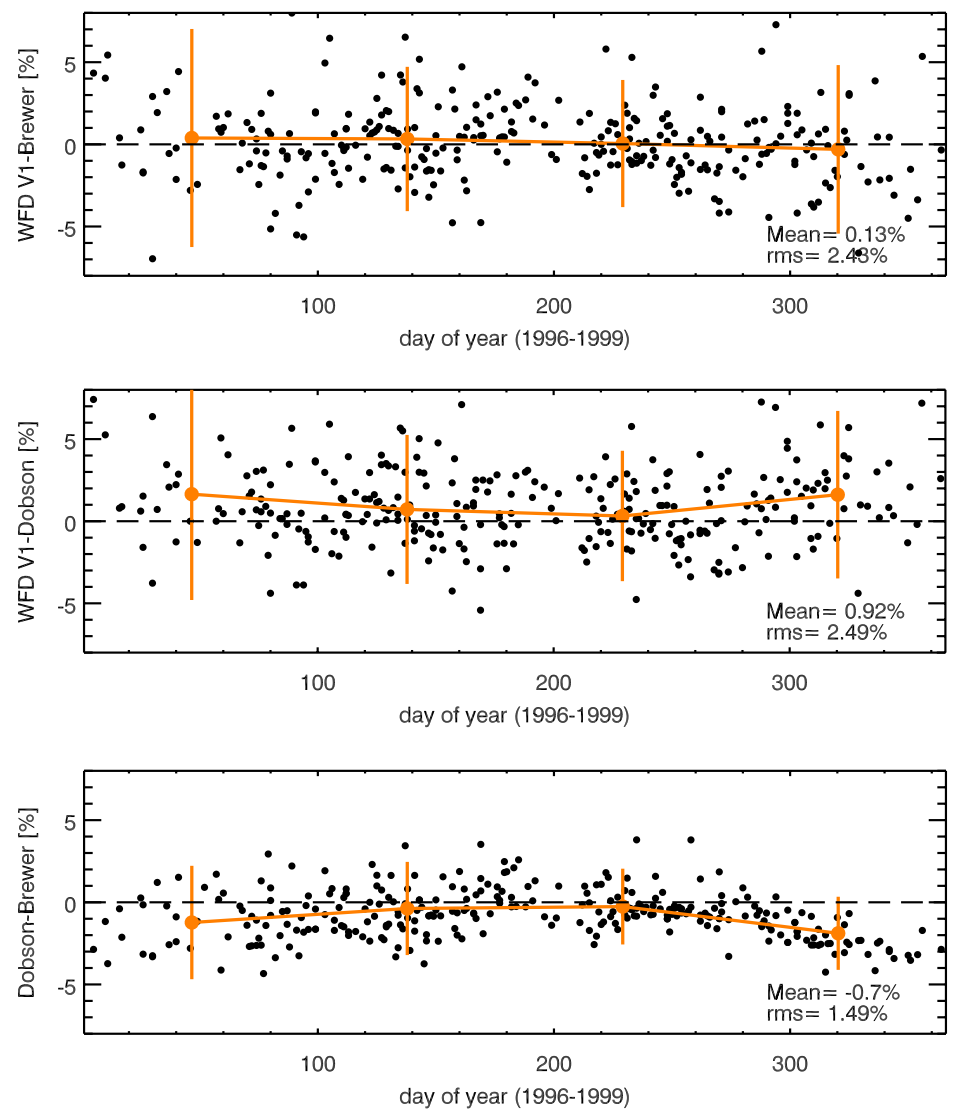

Fig. 3. Annual course of differences between GOME WFDOAS V1, single Brewer, and Dobson data at Hradec Kralove shown for all possible pair combinations. Top: WFDOAS minus Brewer. Middle: WFDOAS minus Dobson, Bottom: Dobson minus Brewer.

maximum of $+1.5 \%$ during winter and $0 \%$ difference in summer. WFDOAS results appear to exhibit only a very small seasonal variation with respect to the Brewer.

Similar conclusions can be derived from the comparison with the ground-based data from Hradec Kralove. In Fig. 3 different combinations of differences between satellite and ground-based data are shown. The top two panels show differences of WFDOAS with respect to Brewer and Dobson, while the lowermost panel depicts the differences between average Dobson and Brewer results from the same day.

The WFDOAS bias with respect to Brewer is less than $0.2 \%$ and a very weak seasonal cycle of $\pm 0.5 \%$ like in the Meteorological Observatory Hohenpeissenberg (MOHp) data is evident here. A somewhat larger seasonal variation is observed if compared to Dobson $( \pm 1 \%)$. This is in line with the earlier comparison to MOHp. Note that the percentage scale is finer (smaller) in these plots as compared to the MOHp plots; the RMS scatter of the differences remains about the same.

When comparing data from both stations it is noticeable that the Hradec Kralove Dobson is $0.5 \%$ lower on average than the same instrument at MOHp. A new set of calibration settings were introduced in Hradec Kralove in 1997 that were not adopted at MOHp (U. Köhler, DWD, personal communication, see also Staehelin et al., 2003) and that may explain this bias. The change in the calibration settings is also noticeable from the longterm times series in the Dobson-Brewer differences at Hradec Kralove that showed less variability in 1996 and earlier (Staehelin et al., 2003, see their Fig. 5).

A distinct seasonal cycle in the Dobson-Brewer differences is noticed with maxima in winter and minima (near zero) in summer. The major contribution to this seasonal cycle in Dobson-Brewer differences is due to the use of different wavelength pairs in both instruments to retrieve ozone. Particularly, the $\mathrm{D}$ pair ratio of the $\mathrm{O}_{3}$ cross-sections $(317.6 / 339.8 \mathrm{~nm})$ as used by the Dobson shows the largest temperature dependence of all ratios used in the standard retrieval by both instruments (Staehelin et al., 2003). However, a fixed temperature $(226.9 \mathrm{~K})$ ozone cross-section is applied in the standard retrieval so that stratospheric temperature variation with season is not accounted for. During winter stratospheric temperatures are well below $226.9 \mathrm{~K}$ that may explain the larger differences between Dobson and Brewer. The observed differences between GOME and Dobson are therefore consistent with the expectation from the neglect of temperature corrections in the standard retrieval. Due to the 
reduced temperature sensitivity of the Brewer wavelengths, it is also not unexpected that GOME WFDOAS agrees better with Brewer. It should be also noted that the temperature sensitivity is also larger with direct sun than with zenith sky ground-based observations (Vanicek, 1998).

\section{Comparison with individual WOUDC stations}

Forty-two stations have been selected from the WOUDC data base (Hare and Fioletov, 1998; Fioletov et al., 1999) for global validation of WFDOAS V1.0. The stations are summarised in Table 1. Only those stations have been selected that show no larger gaps in time and should not suffer from unreasonable short time jumps and do not have an average bias clearly exceeding 5\%. Those excluded were mainly a few Indian stations and Hanoi, Vietnam. Particularly at northern hemispheric mid latitudes, many more stations were available but a fairly even distribution in longitudes were ensured by selecting 19 stations out of this data set. The majority of data are from Dobson measurements. The maximum collocation radius was here set to $300 \mathrm{~km}$ (between centre of GOME footprint and station) and only the nearest GOME overpass was used at a given day. The same data set has been used in a recent paper validating the GOME V2.7 data version (Bramstedt et al., 2003). A change of collocation radius to $300 \mathrm{~km}$ rather than $160 \mathrm{~km}$ as in the case of the triple comparison presented earlier does not alter the statistics significantly. For each climate zone (in $30^{\circ}$ steps) a representative station has been selected and the differences are shown as a function of time from 1996 to 1999 in Fig. 4. The stations are from north to south; Resolute $\left(\right.$ Canada, $\left.75^{\circ} \mathrm{N}\right)$, Boulder (USA, $40^{\circ} \mathrm{N}$ ), Singapore $\left(1^{\circ} \mathrm{N}\right)$, Comodoro Rivadavia (Argentina, $46^{\circ} \mathrm{S}$ ), and Syowa, the Japanese station in Antarctica $\left(69^{\circ} \mathrm{S}\right)$. Also shown are the three month mean time series (in orange) in order to visualise possible seasonal variability and a longterm drift in the data. The orange bars indicate the $2 \sigma$ scatter in the three month mean differences. As with earlier versions of GOME total ozone and as shown later for WFDOAS in Sect. 5, the time series of GOME-station differences show no significant long-term drift (GDP V3 VALREPORT, 2002; Bramstedt et al., 2003).

Both mid latitude stations in both hemispheres as well as the data from Singapore have an average bias over the four year period that is well below $\pm 0.5 \%$. Outside the polar regions no significant seasonal signature in the differences is detectable with the exception of Boulder. The Boulder difference series, however, has a distinct seasonal cycle of up to $\pm 1.5 \%$ starting in 1997 that is not apparent in 1996. As discussed in the previous section it could be related to the change in calibration settings that many stations introduced to their Dobson spectrophotometers in 1997. The seasonal signature in Boulder is quite similar to that observed with Hradec Kralove and MOHp Dobsons with maximum in northern hemispheric winter (January, February, March) and minimum in summer (July, August, September).
Table 1. List of WOUDC station data used in the WFDOAS validation and division into climate zones. The type of instruments are given in the second column: D stands for Dobson, B for Brewer, and $\mathrm{F}$ for the M-124 filter instruments.

\begin{tabular}{|c|c|c|c|c|c|}
\hline $\begin{array}{c}\text { Station } \\
\text { No. }\end{array}$ & Type & Latitude & Longitude & $\begin{array}{r}\text { Height } \\
{[\mathrm{m}]}\end{array}$ & Location \\
\hline \multicolumn{6}{|c|}{$\mathrm{NH}$ polar region } \\
\hline 024 & B & $74.72^{\circ} \mathrm{N}$ & $94.98^{\circ} \mathrm{W}$ & 65 & Resolute \\
\hline 199 & $\mathrm{D}$ & $71.32^{\circ} \mathrm{N}$ & $156.6^{\circ} \mathrm{W}$ & 11 & Barrow \\
\hline 105 & $\mathrm{D}$ & $64.82^{\circ} \mathrm{N}$ & $147.87^{\circ} \mathrm{W}$ & 138 & Fairbanks \\
\hline 051 & $\mathrm{D}$ & $64.13^{\circ} \mathrm{N}$ & $21.9^{\circ} \mathrm{W}$ & 75 & Reykjavik \\
\hline 123 & B & $62.08^{\circ} \mathrm{N}$ & $129.75^{\circ} \mathrm{E}$ & 98 & Yakutsk \\
\hline 043 & $\mathrm{D}$ & $60.13^{\circ} \mathrm{N}$ & $1.18^{\circ} \mathrm{W}$ & 95 & Lerwick \\
\hline \multicolumn{6}{|c|}{$\mathrm{NH}$ mid latitude region } \\
\hline 077 & B & $58.75^{\circ} \mathrm{N}$ & $94.07^{\circ} \mathrm{W}$ & 35 & Churchill \\
\hline 143 & $\mathrm{~F}$ & $56.00^{\circ} \mathrm{N}$ & $92.88^{\circ} \mathrm{E}$ & 137 & Krasnoyarsk \\
\hline 021 & B & $53.55^{\circ} \mathrm{N}$ & $114.10^{\circ} \mathrm{W}$ & 766 & Edmonton \\
\hline 076 & B & $53.32^{\circ} \mathrm{N}$ & $60.38^{\circ} \mathrm{W}$ & 44 & Goose Bay \\
\hline 130 & $\mathrm{~F}$ & $52.97^{\circ} \mathrm{N}$ & $158.75^{\circ} \mathrm{E}$ & 78 & Petropavlovsk \\
\hline 174 & B & $52.22^{\circ} \mathrm{N}$ & $14.12^{\circ} \mathrm{E}$ & 112 & Lindenberg \\
\hline 053 & $\mathrm{D}$ & $50.80^{\circ} \mathrm{N}$ & $4.35^{\circ} \mathrm{E}$ & 100 & Uccle \\
\hline 036 & D & $50.22^{\circ} \mathrm{N}$ & $5.32^{\circ} \mathrm{W}$ & 88 & Camborne \\
\hline 099 & $\mathrm{D}$ & $47.80^{\circ} \mathrm{N}$ & $11.02^{\circ} \mathrm{E}$ & 975 & H'peissenberg \\
\hline 277 & $\mathrm{~F}$ & $47.73^{\circ} \mathrm{N}$ & $42.25^{\circ} \mathrm{E}$ & 64 & Cimljansk \\
\hline 020 & D & $46.87^{\circ} \mathrm{N}$ & $68.02^{\circ} \mathrm{W}$ & 192 & Caribou \\
\hline 119 & $\mathrm{~F}$ & $46.48^{\circ} \mathrm{N}$ & $30.63^{\circ} \mathrm{E}$ & 42 & Odessa \\
\hline 065 & $\mathrm{D}$ & $43.78^{\circ} \mathrm{N}$ & $79.47^{\circ} \mathrm{W}$ & 198 & Toronto \\
\hline 012 & $\mathrm{D}$ & $43.05^{\circ} \mathrm{N}$ & $141.33^{\circ} \mathrm{E}$ & 19 & Sapporo \\
\hline 067 & $\mathrm{D}$ & $40.02^{\circ} \mathrm{N}$ & $105.25^{\circ} \mathrm{W}$ & 1390 & Boulder \\
\hline 208 & D & $39.77^{\circ} \mathrm{N}$ & $117.00^{\circ} \mathrm{E}$ & 80 & Xianghe \\
\hline 293 & $\mathrm{D}$ & $39.45^{\circ} \mathrm{N}$ & $22.48^{\circ} \mathrm{E}$ & 110 & Athens \\
\hline 107 & $\mathrm{D}$ & $37.93^{\circ} \mathrm{N}$ & $75.48^{\circ} \mathrm{W}$ & 13 & Wallops Island \\
\hline 158 & B & $33.57^{\circ} \mathrm{N}$ & $7.67^{\circ} \mathrm{W}$ & 55 & Casablanca \\
\hline \multicolumn{6}{|l|}{ Tropics } \\
\hline 031 & D & $19.53^{\circ} \mathrm{N}$ & $155.57^{\circ} \mathrm{W}$ & 3420 & Mauna Loa \\
\hline 187 & $\mathrm{D}$ & $18.53^{\circ} \mathrm{N}$ & $73.85^{\circ} \mathrm{E}$ & 559 & Poona \\
\hline 218 & $\mathrm{D}$ & $14.63^{\circ} \mathrm{N}$ & $121.83^{\circ} \mathrm{E}$ & 61 & Manila \\
\hline 214 & $\mathrm{D}$ & $1.33^{\circ} \mathrm{N}$ & $103.88^{\circ} \mathrm{E}$ & 14 & Singapore \\
\hline 175 & D & $1.27^{\circ} \mathrm{S}$ & $36.8^{\circ} \mathrm{E}$ & 1745 & Nairobi \\
\hline 219 & $\mathrm{D}$ & $5.84^{\circ} \mathrm{S}$ & $35.21^{\circ} \mathrm{W}$ & 32 & Natal \\
\hline 084 & $\mathrm{D}$ & $12.42^{\circ} \mathrm{S}$ & $130.88^{\circ} \mathrm{E}$ & 31 & Darwin \\
\hline 191 & D & $14.25^{\circ} \mathrm{S}$ & $170.56^{\circ} \mathrm{W}$ & 82 & Samoa \\
\hline 200 & $\mathrm{D}$ & $22.68^{\circ} \mathrm{S}$ & $45.00^{\circ} \mathrm{W}$ & 573 & C. Paulista \\
\hline \multicolumn{6}{|c|}{ SH mid latitude } \\
\hline 027 & $\mathrm{D}$ & $27.42^{\circ} \mathrm{S}$ & $153.12^{\circ} \mathrm{E}$ & 18 & Brisbane \\
\hline 343 & D & $31.38^{\circ} \mathrm{S}$ & $57.97^{\circ} \mathrm{W}$ & 31 & Salto \\
\hline 091 & D & $34.58^{\circ} \mathrm{S}$ & $58.48^{\circ} \mathrm{W}$ & 25 & Buenos Aires \\
\hline 253 & $\mathrm{D}$ & $37.80^{\circ} \mathrm{S}$ & $144.97^{\circ} \mathrm{E}$ & 125 & Melbourne \\
\hline 256 & $\mathrm{D}$ & $45.06^{\circ} \mathrm{S}$ & $169.70^{\circ} \mathrm{E}$ & 370 & Lauder \\
\hline 342 & $\mathrm{D}$ & $45.78^{\circ} \mathrm{S}$ & $67.5^{\circ} \mathrm{W}$ & 43 & C. Rivadavia \\
\hline 339 & D & $54.85^{\circ} \mathrm{S}$ & $68.31^{\circ} \mathrm{W}$ & 7 & Ushuaia \\
\hline \multicolumn{6}{|c|}{ Antarctica } \\
\hline 233 & $\mathrm{D}$ & $64.23^{\circ} \mathrm{S}$ & $56.72^{\circ} \mathrm{W}$ & 196 & Marambio \\
\hline 101 & $\mathrm{D}$ & $69.00^{\circ} \mathrm{S}$ & $39.58^{\circ} \mathrm{E}$ & 21 & Syowa \\
\hline 057 & $\mathrm{D}$ & $73.51^{\circ} \mathrm{S}$ & $26.73^{\circ} \mathrm{W}$ & 31 & Halley Bay \\
\hline 268 & D & $77.83^{\circ} \mathrm{S}$ & $166.68^{\circ} \mathrm{E}$ & 250 & Arrival Heights \\
\hline
\end{tabular}

In Comodoro Rivadavia, Argentina, a seasonal signature is not clearly discernible, except for occasional larger deviations that are not repeated in other years. This is most likely related to interruptions in measurements in southern hemispheric summer (January, February, March), so that only few data contributed to the three month average as in 1997 and 1999. 

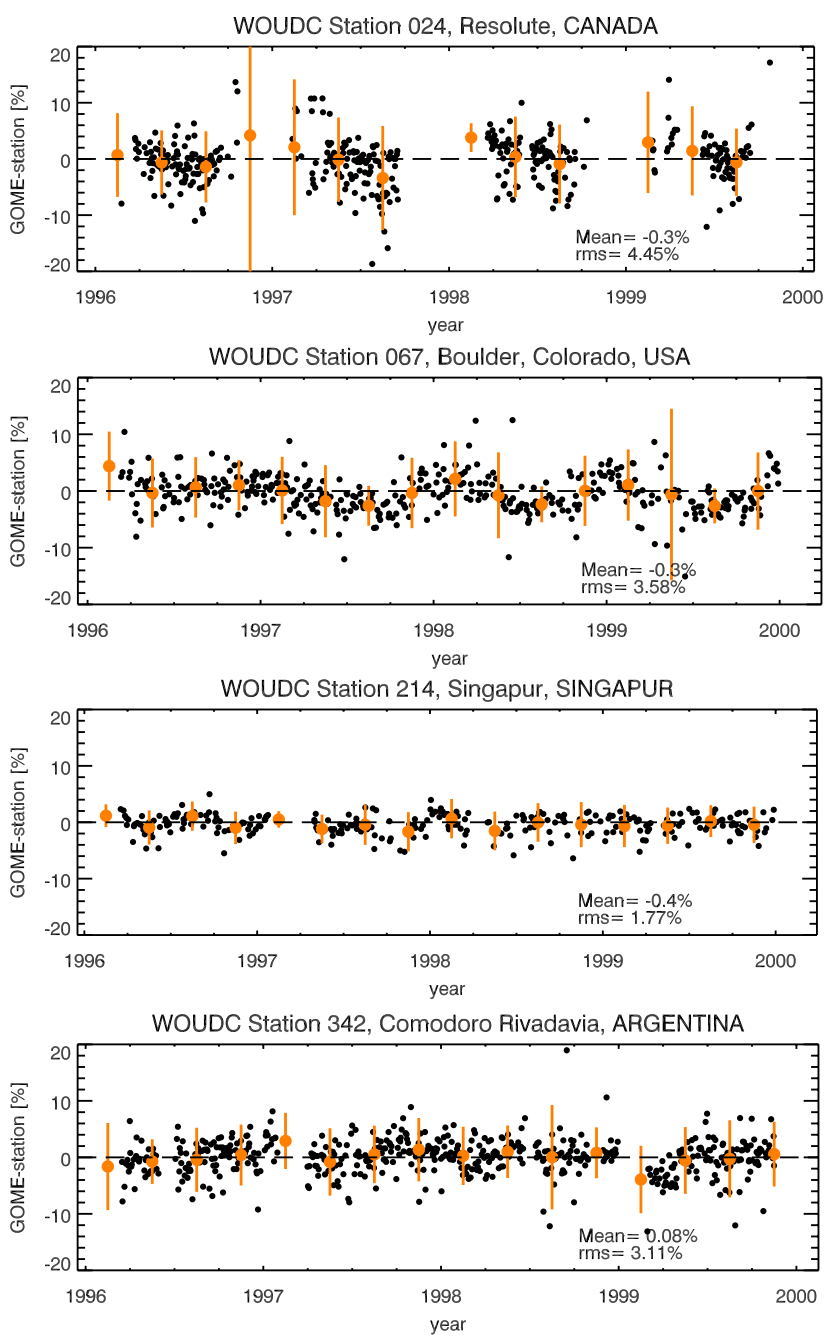

WOUDC Station 101, Syowa, ANTARCTICA

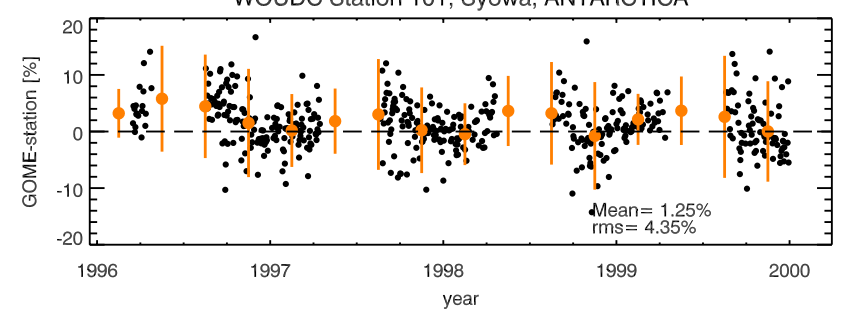

Fig. 4. Daily differences between collocated GOME WFDOAS V1.0 and various ground stations distributed from north to south between 1996 and 1999. Orange points mark three month averages and error bars the $2 \sigma$ RMS in the observed differences. All station data are from Dobsons except for Resolute that are Brewer measurements.

The two stations in the south and north polar regions, Syowa and Resolute, show a distinct annual cycle in the GOME-ground station differences. Average differences in spring/summer are quite low (below 1\%) but can increase to $+5 \%$ close to the polar night terminator. It is noted that this
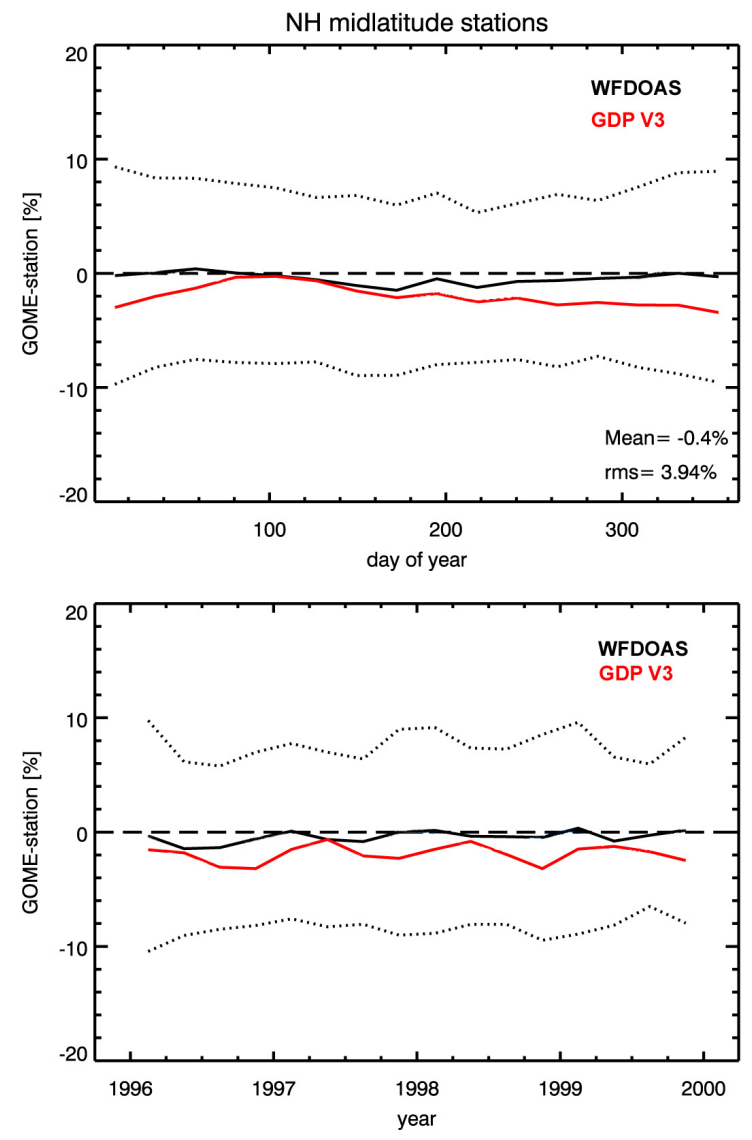

Fig. 5. Average of WFDOAS V1.0 and GDP V3.0 differences to nineteen NH mid latitude WOUDC stations: 1996-1999. Top: annual course, bottom: all years. The dotted lines show the $2 \sigma$ RMS in the WFDOAS differences to the ground data from averaging.

pattern is symmetric about the polar night period, although total ozone under ozone hole conditions in spring is much lower than in fall. The large gradients in ozone observed near the polar vortex edge is responsible for the larger scatter in the southern hemispheric (SH) spring, because both GOME and surface instrument do not look at the same airmass. In fall 1997 the scatter in the differences to the Resolute Brewer data is quite large as expressed by the huge vertical bar in Fig. 4. This is due to some outliers and due to the fact that close to the polar night period only few data are contributing to the three month mean. In Sect. 6 the validation in polar regions and under ozone hole condition is discussed in more detail.

\section{Validation at low to middle latitudes}

For a statistical analysis WFDOAS total ozone has been compared with ground based data from 42 stations as listed in Table 1. The comparisons have been separated according to climate zones: high latitudes $\left(60^{\circ}-90^{\circ}\right)$ and mid latitudes 


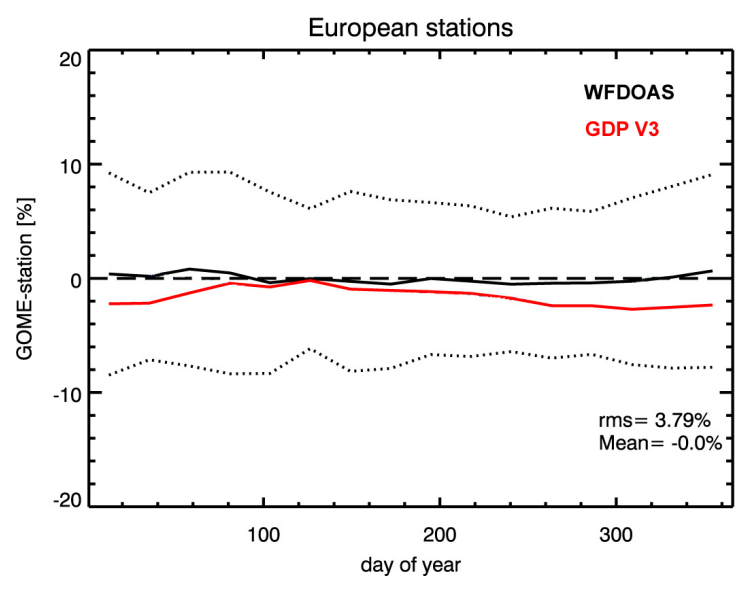

Fig. 6. Same as Fig. 5, but for eight European stations (Arosa, Lindenberg, Potsdam, Hohenpeissenberg, Hradec Kralove, Uccle, Camborne, and Oslo), see text for further details.
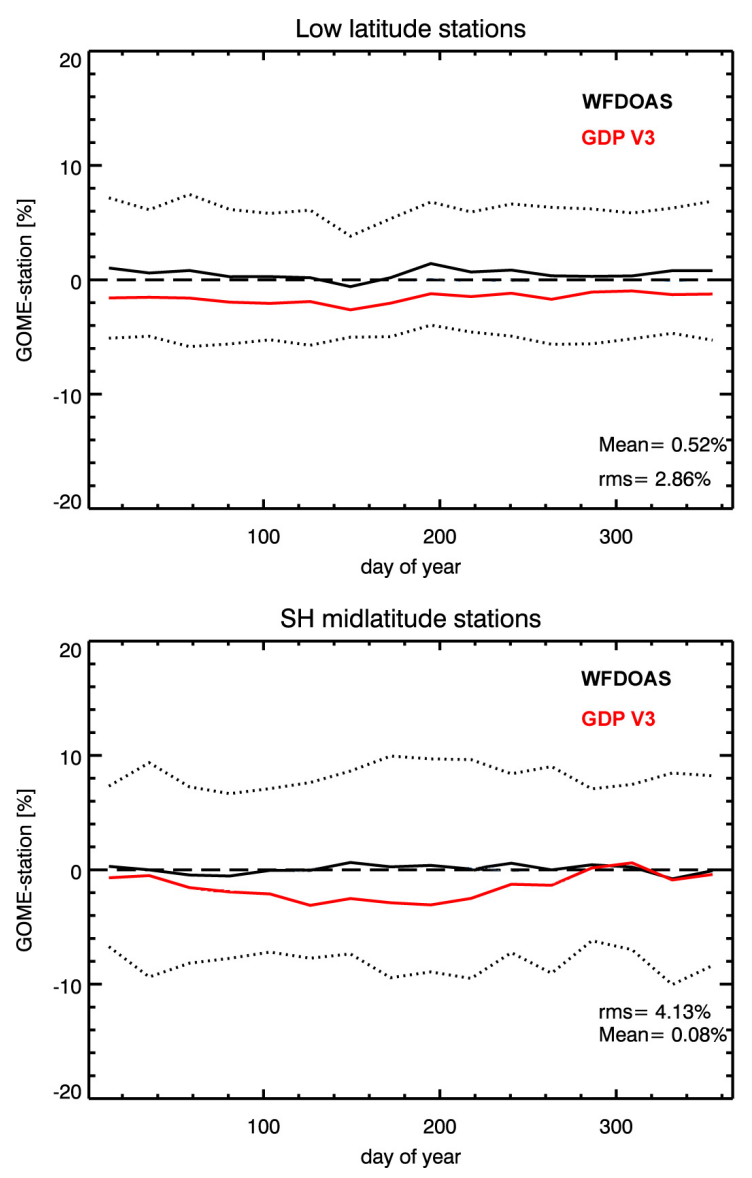

Fig. 7. Annual course of differences between GOME and ground stations for tropics (top) and SH mid latitudes (bottom). The dotted lines show the $2 \sigma$ RMS in the WFDOAS differences to the ground data from averaging. $\left(30^{\circ}-60^{\circ}\right)$ in each hemisphere and tropics $\left(25^{\circ} \mathrm{S}-25^{\circ} \mathrm{N}\right)$ according to the grouping of stations as shown in Table 1 . Figures 5 to 7 show the summary of the comparisons between WFDOAS and ground based data in each climate zone except for the high latitude results that are presented in the next section. The dotted lines in those figures show the $2 \sigma$ spread from averaging over all differences between collocated satellite and ground data. For documenting the improvement achieved with WFDOAS, the same comparison has been made with the operational GOME Data Processor Version 3.0 (short: GDP V3) that are shown in red in Figs. 57. A detailed description of GDP V3 can be found in GDP V3 VALREPORT, 2002.

A plot summarising the comparison between different satellite analyses, WFDOAS and GDP V3 with nineteen mid latitude stations is shown in Fig. 5. The average annual bias is $-0.4 \%$ for WFDOAS. A small seasonal variation of about $\pm 0.5 \%$ can be seen, with maximum differences in winter and minimum difference in summer statistically confirming the results from the individual station comparison. The GDP V3.0 shows an annual variability of $\pm 1 \%$ with a bias of around $-1 \%$ with respect to the station data. However, the maximum and minimum in GDP V3 differences are shifted towards spring and fall, respectively.

By looking at individual mid latitude stations, it can be noted that for some stations the seasonal variation in the differences is absent (e.g. Dobsons in Uccle, Belgium, and Lauder, New Zealand), while for other stations a weak seasonal cycle is observed with WFDOAS. In order to see the effect on the statistics by selecting different stations, the comparison has been limited to eight European stations (Arosa, Lindenberg, Potsdam, Hohenpeissenberg, Hradec Kralove, Uccle, Camborne, and Oslo) and Russian stations that mainly operate the so-called M-124 filter spectrometers to measure ozone (Gushchin et al., 1985) have been excluded. Almost no seasonal variation is observed in the WFDOAS mean differences to the European stations, while the seasonal cycle in the GDP V3 differences still remains as shown in Fig. 6.

The annual course of the GOME differences to the groundbased data for tropical and $\mathrm{SH}$ mid latitude stations (see Table 1) is shown in Fig. 7. The SH mid latitude differences show a similar pattern (now shifted by six months) as observed in the northern hemisphere (NH, see Fig. 5). The WFDOAS differences like in the NH mid latitudes show no significant annual cycle. The mean bias in low and mid latitudes is less than $0.5 \%$ for WFDOAS V1.0.

The insignificant seasonal variation observed in the WFDOAS differences at mid latitudes is in contrast to the conclusion from the triple intercomparison involving collocated Brewer and Dobson data, where a distinct seasonal cycle signature is expected from the lack of ozone temperature correction in the ground based data retrieval. One should keep in mind that other factors influence Dobson results such as stray light errors (reduces retrieved total ozone) and environmental settings (affecting stray light levels) that may differ from 
station to station. As pointed out earlier, the ozone temperature correction is more important in direct sun measurements than for zenith sky measurements that are also included in the WOUDC data. An important result from this validation is, nevertheless, that the seasonal dependence in the GOMEground based data differences is quite small and gets smeared out when averaged over many stations. This is a large improvement compared to GDP V3 that shows a distinct seasonal signatures at mid latitudes that does not average out. Both retrievals, WFDOAS and GDP V3, use the TOMS V7 profile shape climatology (GDP V3 uses the climatology for airmass factor calculation). The big improvement in WFDOAS retrieval is that the TOMS V7 ozone profile shape climatology is also used to determine the varying ozone dependent contribution to the rotational Raman correction that is neglected in GDP V3.

A long-term comparison has been carried out with Dobson data from Lauder, $45^{\circ} \mathrm{S}$, and Brewer data from Hohenpeissenberg, $48^{\circ} \mathrm{N}$. The WFDOAS time series along with the Lauder Dobson data is shown in Fig. 8. The Hohenpeissenberg time series has been shown in Fig. 7 of ColdeweyEgbers et al. (2005). All Lauder measurements from zenithsky and direct-sun ground based data have been included. Apart from a bias of $+0.4 \%$ for the entire time period (identical to the bias observed in Hohenpeissenberg), no significant seasonal variation, like in the comparison with Hohenpeissenberg, is seen in the comparison with WFDOAS V1.0. Lower stratospheric temperature seasonal variation is quite small in this region (below $5 \mathrm{~K}$ over the course of the year), such that the lack of seasonal variation in the differences between WFDOAS and Lauder Dobson is not surprising. The bottom panel in Fig. 8 shows the same comparison but with GDP V3.0, where a distinct seasonal cycle is evident for all years. The amplitude from fitting a cosine curve (solid orange line) is $1.7 \%$. For Hohenpeissenberg the amplitude was found to be $1.4 \%$ for GDP V3 (not shown). From this limited comparison (two stations) up to 2003, it can be concluded that the DOAS retrieval in low to middle latitudes does not suffer from the optical degradation that have altered the radiometric accuracy of the GOME instrument particularly in later years (Tanzi et al., 2001).

\section{Validation in polar regions}

Six stations in the north polar region and four stations on Antarctica have been selected for validating polar ozone from GOME (see Table 1). Figure 9 shows the results from the southern hemispheric polar region. The southern polar data show on average a difference of four percent with respect to ground-based data near the polar night period, in some years it can reach on average 10\% like in Antarctic spring 1998. This comparison is difficult since solar elevation angles are low and large ozone gradients near the polar vortex edge, that delineate a cold region where the ozone hole resides, lead to
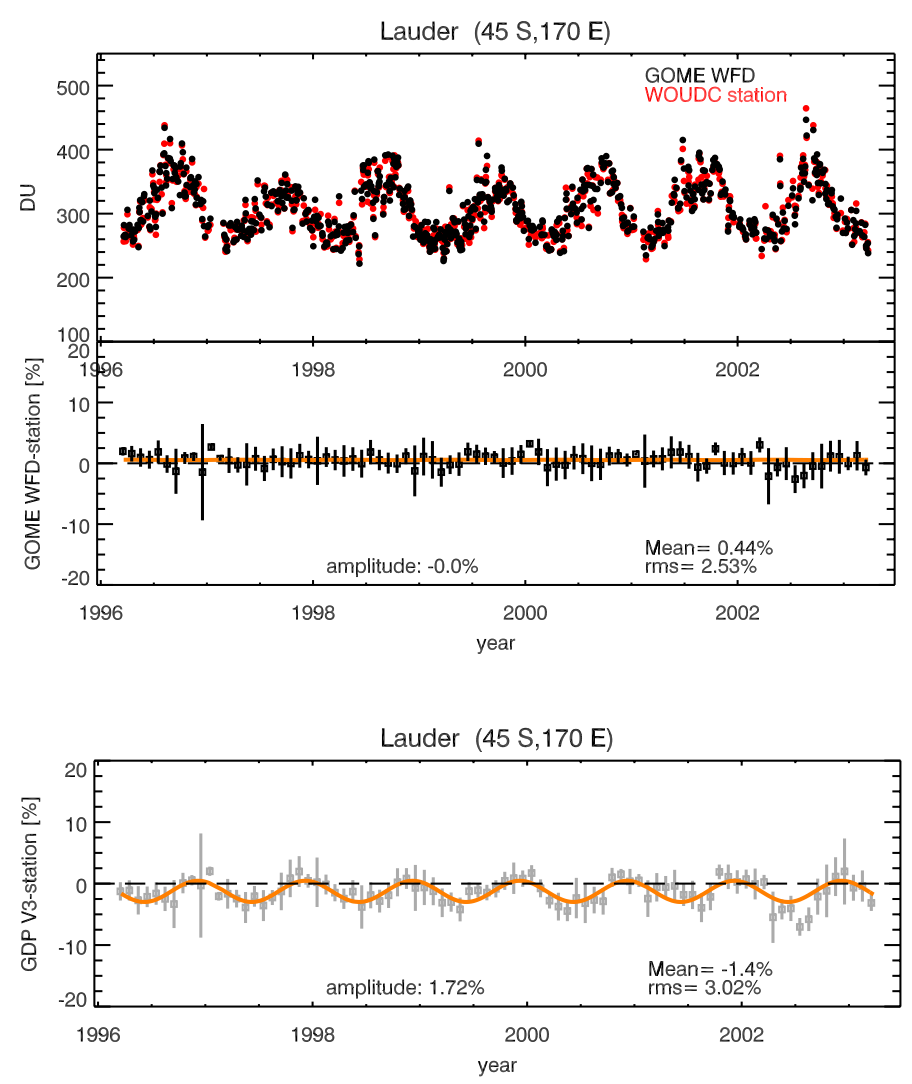

Fig. 8. Longterm comparison between GOME and Lauder Dobson from 1996 to 2003. Top: daily collocated GOME WFDOAS (black) and Dobson data (red) time series. Middle panel: monthly mean differences between WFDOAS and Lauder Dobson in percent. Bottom: same as middle panel, but for GOME GDP V3. Vertical bars indicate the $1 \sigma$ RMS of the daily differences. Orange lines in bottom two panels show the cosine fit to the data to determine the amplitude of the seasonal variation. The amplitude of the cosine term is $0 \%$ and $1.7 \%$ for GOME WFDOAS and GDP V3.0, respectively.

huge scatter in the RMS which can reach a $2 \sigma$ value of $40 \%$ depending on individual stations. Over the annual cycle the average bias is about $0.5 \%$. Comparing these results with GDP V3, one notes that the behaviour near the polar night period is similar for both data versions and, on first sight an improvement by WFDOAS seems only marginal. It is evident that the RMS scatter in the differences is smaller with WFDOAS during austral summer than with GDP V3 and the bias to the station data is lower. Overall, the GDP V3 data seem to be lower than WFDOAS by about $2 \%$ throughout the year. From this view point an improvement with WFDOAS is evident, but the larger discrepancy to ground data near the polar night region (and at high solar zenith angle) remains.

Similar arguments apply to NH polar stations but not as extreme as in the SH (see Fig. 10) due to the absence of the ozone hole regularly observed in the SH. The seasonal 


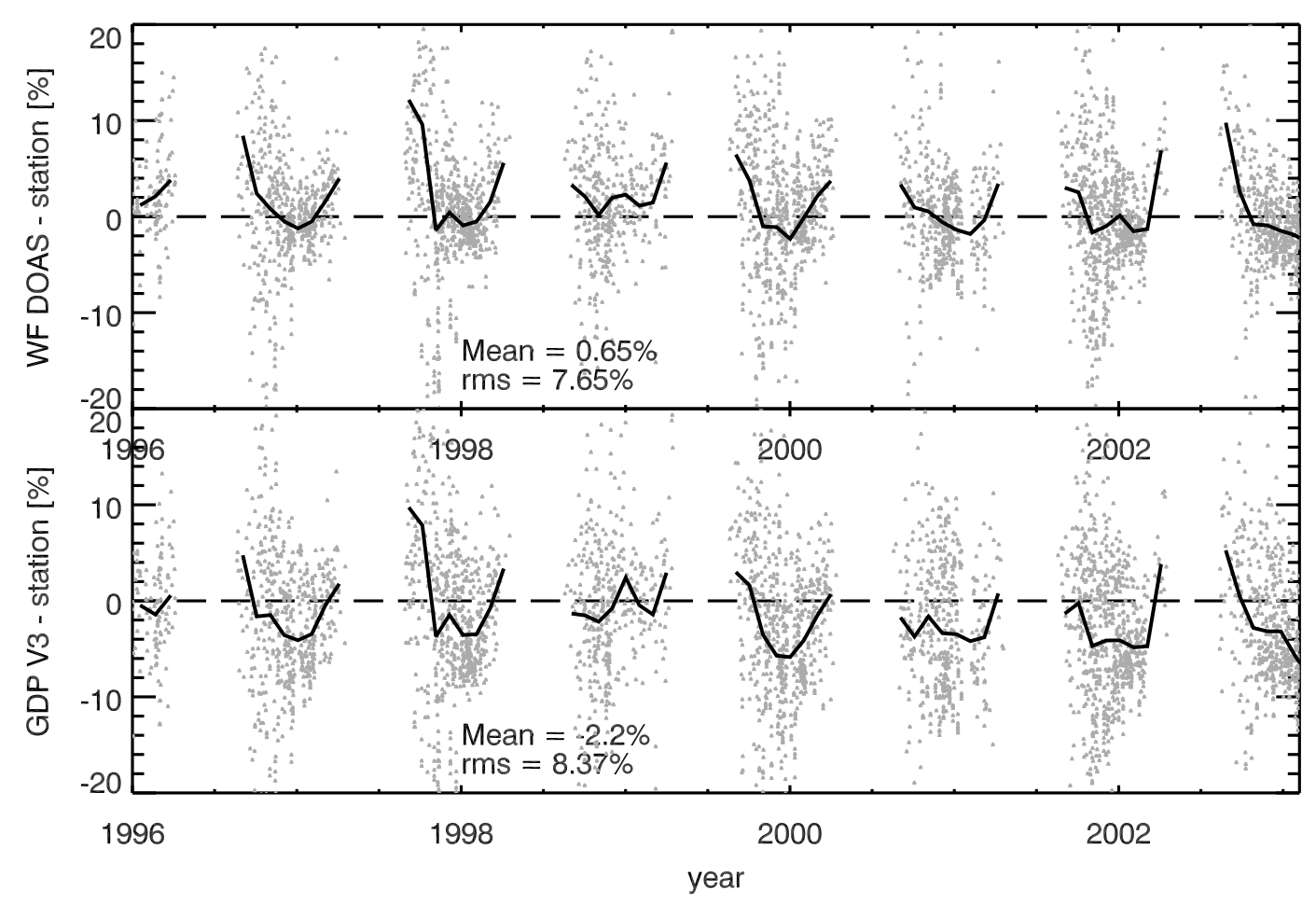

Fig. 9. WFDOAS minus Dobson (top) and GDP V3 minus Dobson (bottom) from 1996 to 2003 for four SH polar stations: Arrival Heights $\left(78^{\circ} \mathrm{S}\right)$, Halley Bay $\left(74^{\circ} \mathrm{S}\right)$, Syowa $\left(69^{\circ} \mathrm{S}\right)$, and Marambio $\left(64^{\circ} \mathrm{S}\right)$. Individual collocations (grey dots) as well as monthly mean differences (solid line) are shown.

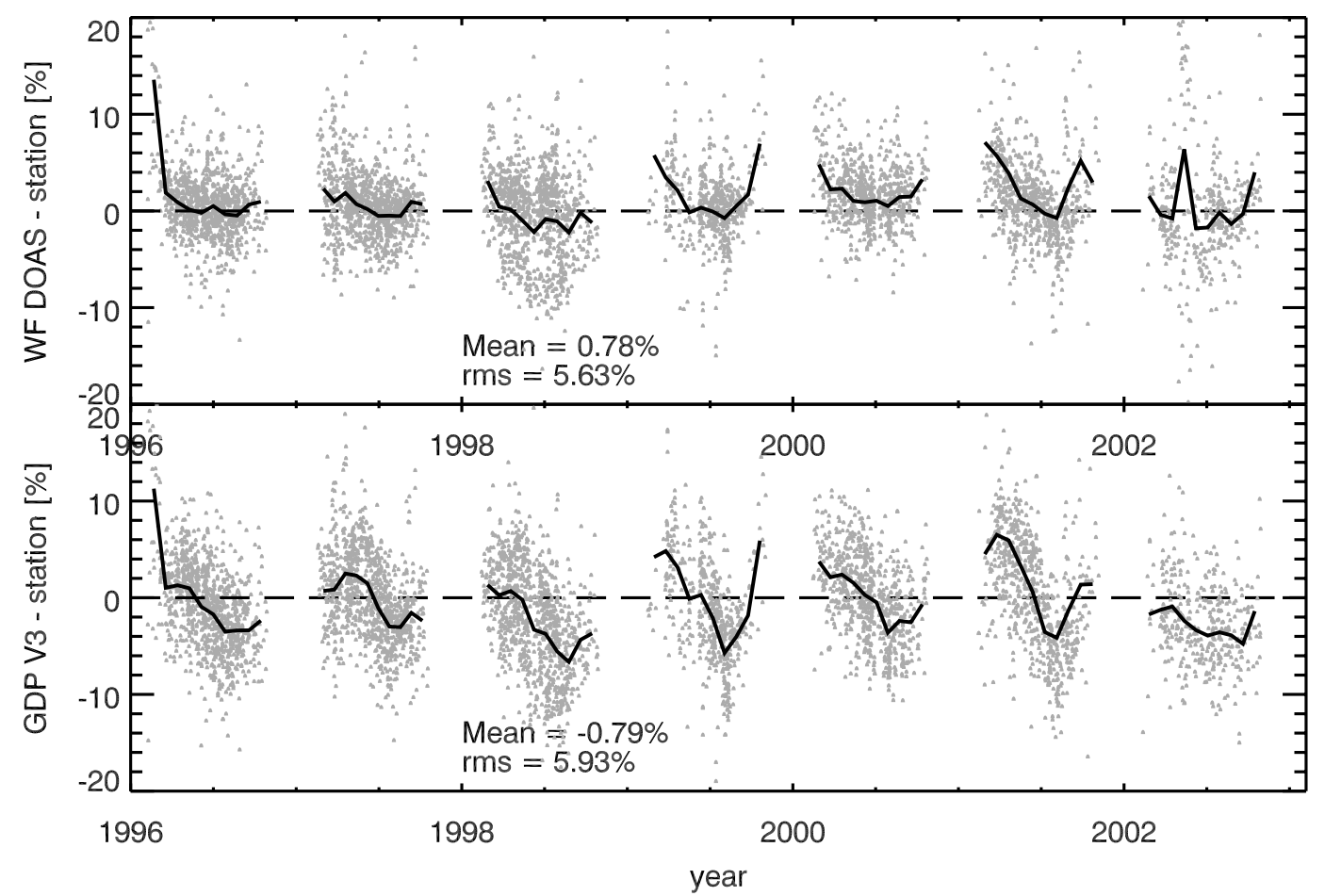

Fig. 10. WFDOAS minus Dobson (top) and GDP V3 minus Dobson (bottom) from 1996 to 2003 for NH polar stations as listed in Table 1. Individual collocations (grey dots) as well as monthly mean differences (solid line) are shown. 


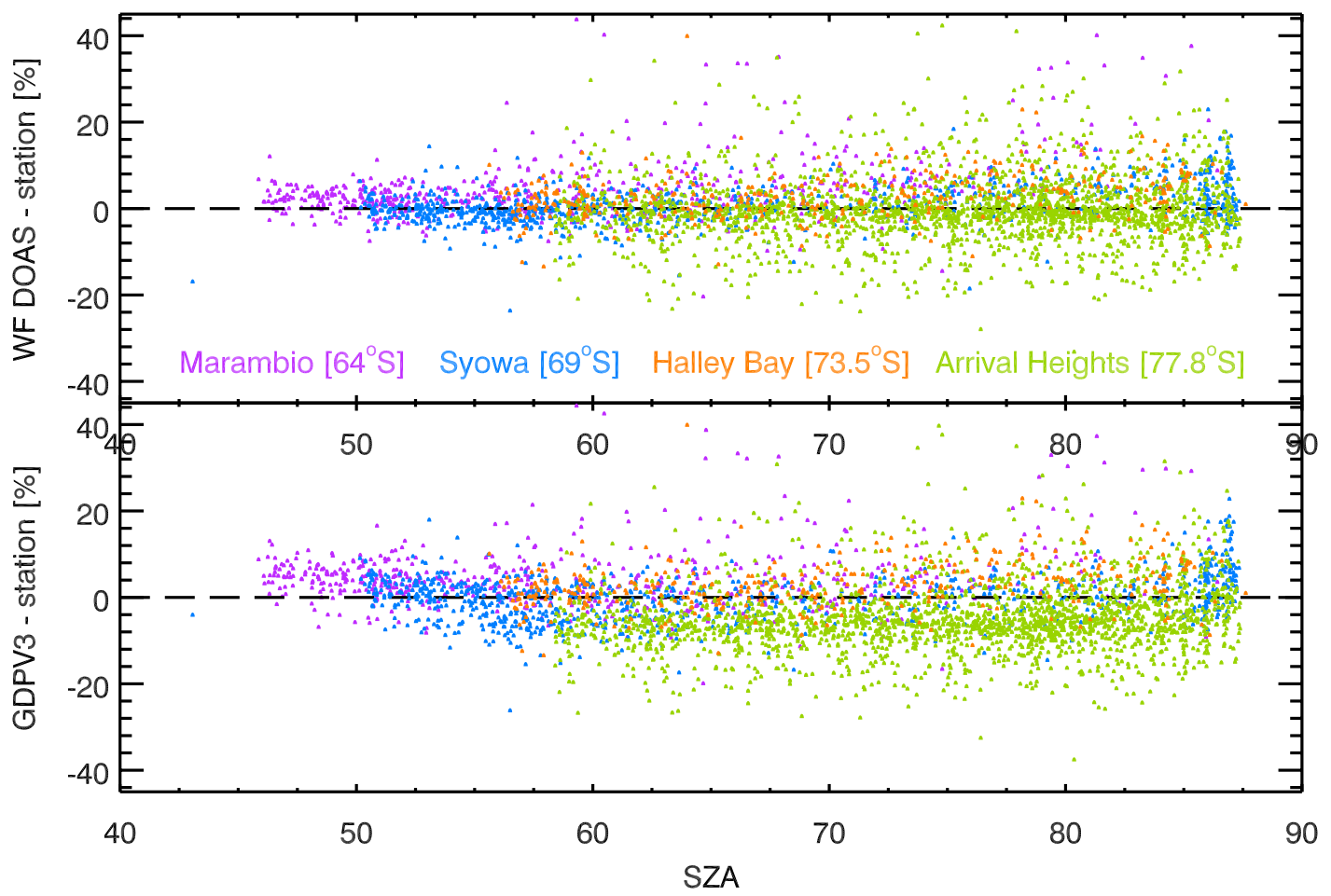

Fig. 11. WFDOAS V1 minus Dobson (top) and GDP V3 minus Dobson (bottom) as a function of solar zenith angle for four SH polar stations: Arrival Heights ( $\left.78^{\circ} \mathrm{S}\right)$, Halley Bay $\left(74^{\circ} \mathrm{S}\right)$, Syowa $\left(69^{\circ} \mathrm{S}\right)$, and Marambio $\left(64^{\circ} \mathrm{S}\right)$.

variation in the differences for both WFDOAS and GDP V3 is very similar to the one observed at mid latitudes with minium differences in summer and maximum differences in winter, but enlarged. Like at mid latitudes the minimum differences are shifted from summer to fall for GDP V3. It is known that the $\mathrm{NH}$ polar ozone shows large interannual variability inside and outside of the polar vortex (see for instance Weber et al., 2002, 2003). The Arctic winter 1997/1998, 1998/1999, 2000/2001 to 2002/03 have been rather warm stratospheric winters with high ozone well beyond $500 \mathrm{DU}$, while 1996/1997 and 1999/2000 were cold stratospheric Arctic winters with lower winter total ozone levels (Weber et al., 2002). The differences to the station data during Arctic winter/spring are highly variable, exceeding $+10 \%$ on average in early 1996 and can be as low as $+2 \%$ in 1997 . A clear trend with time is not observed. It appears that at low solar elevation and higher total ozone the winter differences are on average closer to 5\% (1998/1999 and 2000/2001) and otherwise in most cases closer to +2 to $+3 \%$.

At low solar elevation Dobson instruments suffer from forward scattered stray light and therefore may underestimate the total column. For UV observing satellites like GOME the intensity of the observed scattered light and the signal-tonoise decreases and, therefore, satellite retrieval errors also get larger. Since GOME generally uses larger wavelengths in its retrieval compared to Brewer/Dobsons, the intensity reduction may be lower than for the ground instruments. It is, however, generally difficult for UV/vis instruments to operate in near twilight condition. To reach a better understanding of differences between satellite (TOMS) and groundbased instruments at high-latitudes a measurement campaign involving two Dobson and three Brewer instruments, including single and double Brewers, were carried out in Fairbanks, Alaska, in March/April 2001. Against the travel world standard (Instrument D83, AD pair, direct sun), all Brewer instruments as well as integrated sonde profiles have shown a percent difference of +3 to $+4 \%$ with respect to the world standard (Staehelin et al., 2003) after careful straylight corrections and ozone temperature corrections applied. The Fairbanks direct-sun Dobson results showed a difference of $-1.3 \%$ using the $\mathrm{AD}$ pair and, when using proper ozone temperature and the CD Pair, $a+3.5 \%$ difference with respect to D83 was found. From Fig. 10 it can be seen that in March 2001 the average difference between WFDOAS for all Arctic stations was on the order of +2 to $+4 \%$, that is comparable to the differences observed in the modified Brewer/Dobson retrievals during the TOMS3-F campaign. From a temperature sensitivity of $1.3 \% / 10 \mathrm{~K}$ in the Dobson retrieval and a seasonal variation of about $30 \mathrm{~K}$ in the lower stratosphere a 3-4\% differences could be expected between WFDOAS and Dobsons and also, possibly, between Brewers and Dobsons at high latitudes. This suggests the missing ozone temperature 


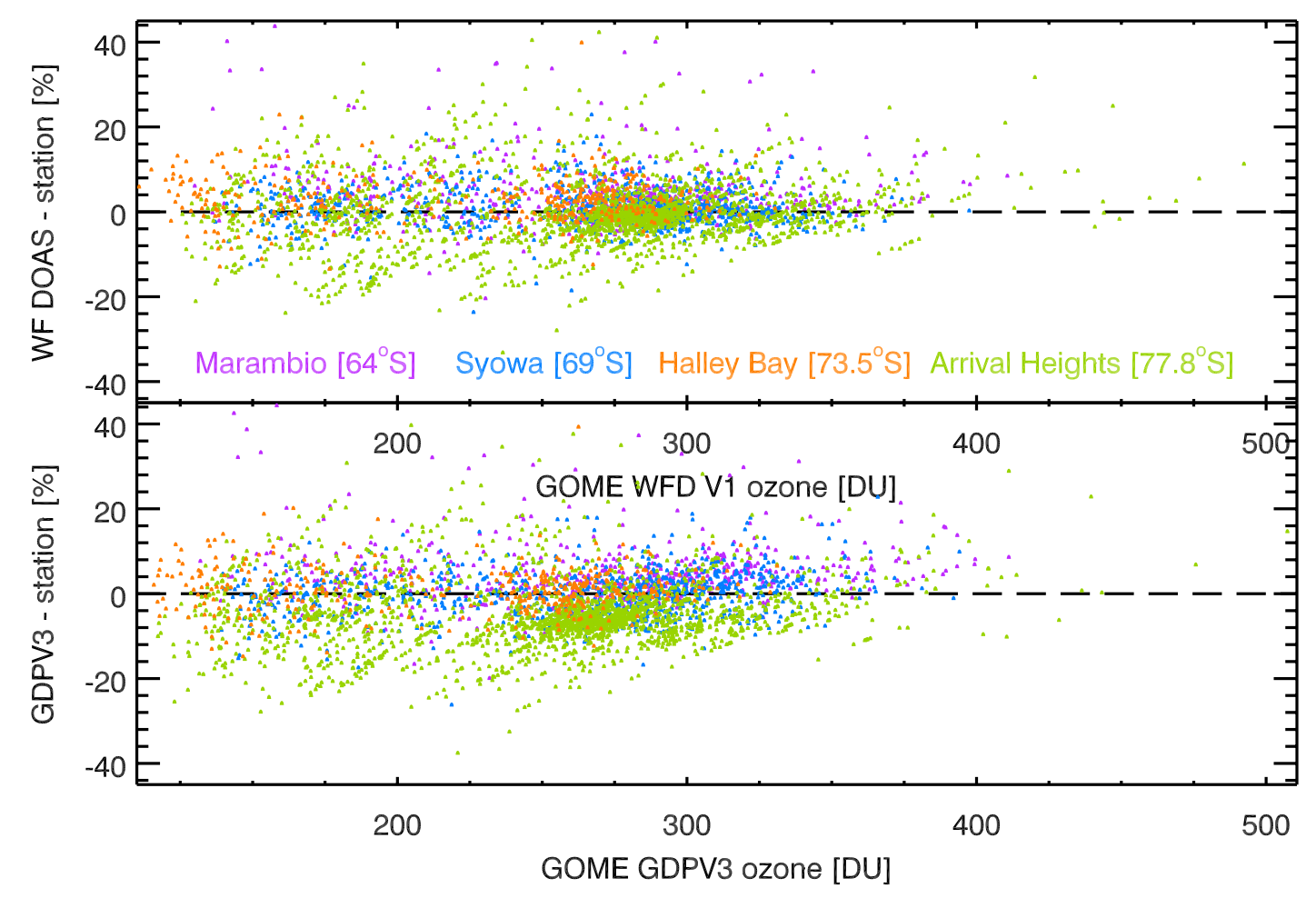

Fig. 12. Same as Fig. 11 but as a function of retrieved total ozone.

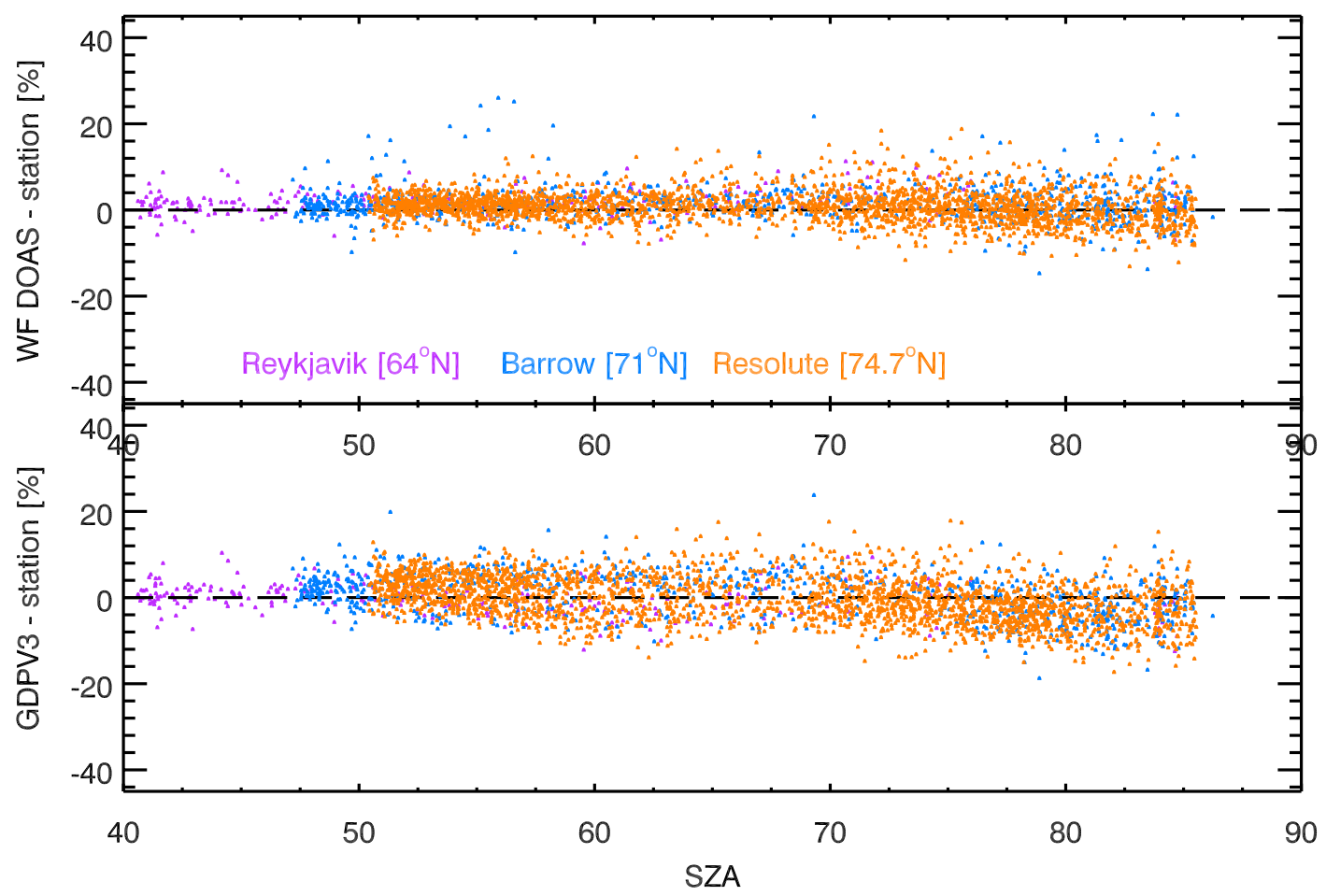

Fig. 13. WFDOAS V1 minus ground based data (top) and GDP V3 - ground based data (bottom) as a function of solar zenith angle for three $\mathrm{NH}$ polar stations: Resolute $\left(75^{\circ} \mathrm{N}\right)$, Barrow $\left(71^{\circ} \mathrm{S}\right)$, and Reykjavik $\left(64^{\circ} \mathrm{N}\right)$. 


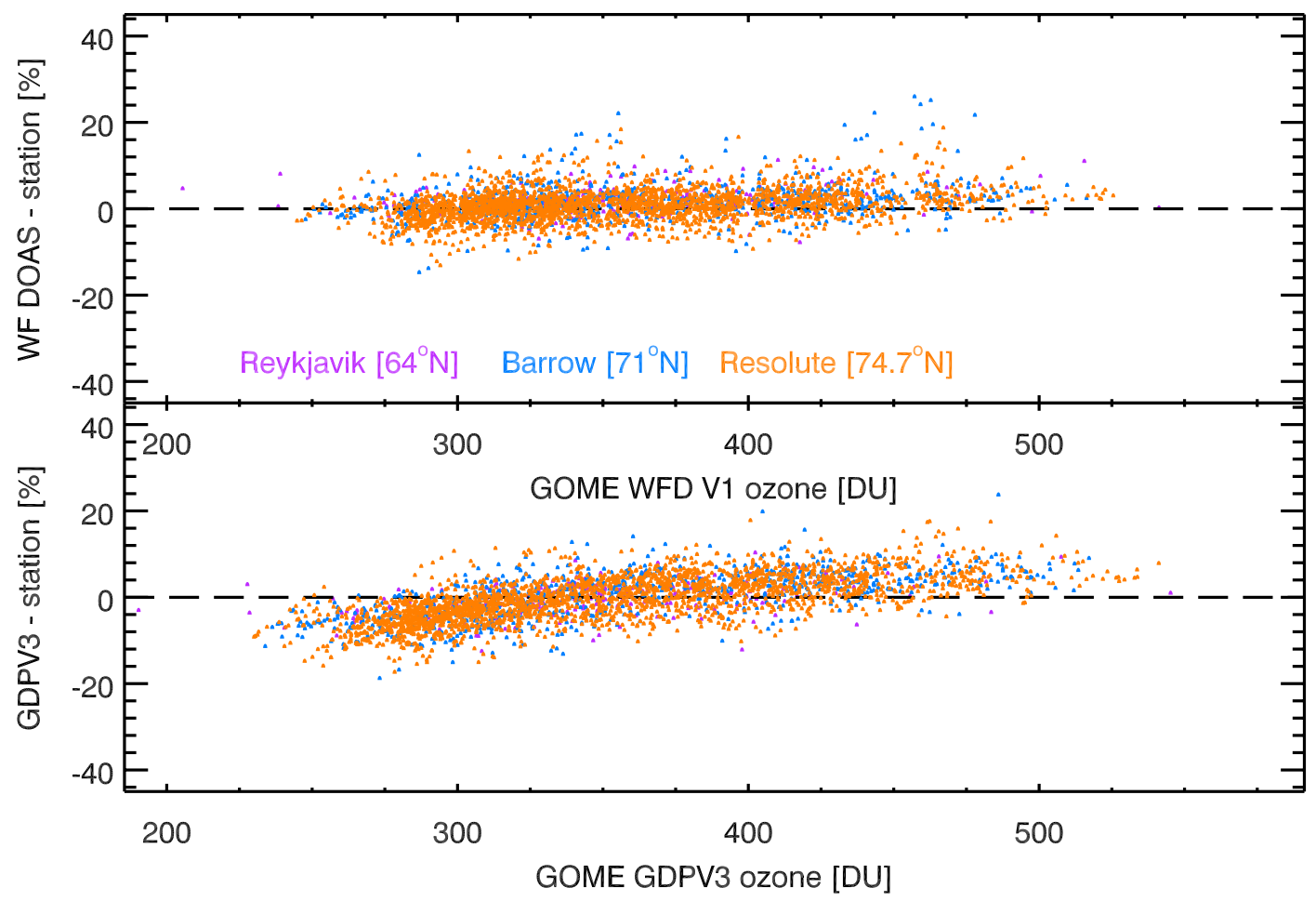

Fig. 14. Same as Fig. 13 but as a function of retrieved total ozone.

correction and stray light issues as a possible explanation for the observed positive bias in WFDOAS differences under low solar elevation condition.

Of particular interest in total ozone monitoring is the development of the Antarctic ozone hole from year-to-year. In the WOUDC statistics four stations from Antarctica have been included for the SH polar stations. It was found that close to the polar night period GOME WFDOAS V1 as well as GDP V3.0 can be up to $10 \%$ higher on average than ground based Dobson. However the variability of the differences is also very large, so that the differences observed may be also to a large extent depend on the station. In Figs. 11 and 12 the results from GOME WFDOAS and Dobson comparison for each of the four Antarctic stations, Syowa, Halley Bay, Marambio, and Arrival Heights, are shown as a function of solar zenith angle and GOME total ozone, respectively. Also depicted are the results for GDP V3 in the bottom panels of each figure. Compared to GDP V3 the WFDOAS differences show a fairly weak dependence to solar zenith angle and total ozone. Looking at the solar zenith angle and total ozone dependence in the $\mathrm{NH}$ polar regions as shown in Figs. 13 and 14, respectively, the improvement achieved by WFDOAS becomes even more striking. The reduced dependence on total ozone and solar zenith angle also confirms the observation of weaker seasonal variation in WFDOAS differences to ground data. Nevertheless, both WFDOAS and GDP V3 retrievals are higher than ground based data near the polar night period that may only to some extent be explained by the problems associated with the standard retrieval applied to ground data.

\section{Conclusions}

The new WFDOAS algorithm for GOME has been extensively compared with globally distributed ground-based data, predominantly Dobson spectrophotometer data. In mid latitudes it agrees on average to within half a percent with WOUDC data. A small negligible seasonal variation of less than $\pm 0.5 \%$ is noted, with a maximum in the differences in fall/winter and a minimum in spring/summer. At several mid latitude stations, e.g. Lauder and Uccle, no seasonal variation is observed. GDP V3 clearly shows a larger and persistent annual variation $( \pm 1 \%)$ but the maximum in the differences is shifted towards spring (minimum in fall). No major changes are observed with the new WFDOAS in the tropics, a constant bias between WFDOAS (below $+1 \%$ ) and GDP (about $-1 \%$ ) with respect to the ground-based data throughout all years are observed.

In polar regions (both hemispheres) larger positive differences are observed with WFDOAS close to the polar night period (on average about $+4 \%$ ). If comparisons are made near the polar vortex edge errors can get quite large (up to $40 \%$ above Antarctica). If both GOME and the station are well inside the ozone hole it appears that the differences are 
below 5\%. Compared to GDP V3, WFDOAS shows large improvements as evident in weaker solar zenith angle and total ozone dependence in the differences to the ground data at high latitudes.

The comparison with Brewer instruments at Hradec Kralove and Hohenpeissenberg has demonstrated excellent agreement with WFDOAS. The maximum in the differences between GOME and Dobson and to a lesser extent with Brewer is related to the fixed ozone temperature used in the standard retrieval of ground based instruments. BrewerDobson differences can be as high as $\pm 2 \%$ (generally on the order of $0.5 \%$ ). This variability gets maximum at high latitudes due to lower solar elevation and the enhanced straylight problem associated with it. The Fairbanks campaign TOMS3-F, where differences of up to 3-4\% between ozone temperature corrected Brewer and standard Dobson were measured in late winter, seems to support this conclusion (Staehelin et al., 2003). The closer agreement of WFDOAS with Brewer than simultaneous Dobson data confirms that the temperature shift weighting function appears appropriate to account for the ozone temperature variation.

Overall it can be concluded that the accuracy of the WFDOAS V1.0 results are now within the uncertainty of the ground-based measurements that make GOME data very attractive for evaluating ground-based network data. The very good agreement with ground based instruments are proof that several issues that has been newly introduced in WFDOAS V1.0 have significantly improved total ozone retrieval and they are listed here in order of importance: 1) variable ozone filling-in as part of the Ring effect, 2) the introduction of an effective scene height from cloud information and 3) derivation of an effective scene albedo from the GOME spectral measurements. The strong dependence in the GOME-Dobson differences in prior versions (Bramstedt et al., 2003) on cloud cover has been significantly improved (not shown here). These changes are, however, not specific to the type of algorithm that has been used here but can be potentially applied to other retrieval schemes as well. The WFDOAS theoretical approach by expanding the differential optical depth equation in a Taylor series is a straight forward formulation of the DOAS inversion and is applicable in a more general way than the standard DOAS approach that uses airmass factors to correct for the slant path geometry like in earlier GOME versions. This algorithm can be also applied to other UV/vis backscatter satellite instruments such as SCIAMACHY (Bovensmann et al., 1999) and OMI (Laan et al., 2000) that measure in continuous scan mode. WFDOAS V1 daily gridded total ozone data can be obtained from www.iup.physik.uni-bremen.de/gome/wfdoas.

Acknowledgements. We thank U. Köhler and H. Claude, MO Hohenpeissenberg, for providing us with their station data (Brewer and Dobson) and for their insights into the ground-based measurements. We also thank B. Evans, NOAA, for providing us data from Lauder and he kindly informed us on the accuracy of the Dobson spectrophotometers. K. Vanicek, Czech Hydrometeorological
Institute, kindly provided Brewer and Dobson data from Hradec Kralove. We also thank him for giving us valuable information on the ground based data. This project was supported in parts by European Space Agency contract 16402/02/I-LG, BMBF grant 7ATF42 (GOMSTRAT) within the AFO2000 national research programme, and EU project EVK2-CT-2001-00133 (CANDIDOZ).

Edited by: T. Koop

\section{References}

Bass, A. M. and Paur, R. J.: The ultraviolet cross-sections of ozone, I, The measurements, in: Atmospheric Ozone, Proc. Quadr. Ozone Symp., Halkidiki, Greece, 1984, edited by: Zerefos, C. and Ghazi, A., Reidel, Dordrecht, 606-610, 1985.

Bovensmann, H., Burrows, J. P., Buchwitz, M., Frerick, J., Noel, S., Rozanov, V. V., Chance, K. V., and Goede, A. H. P.: SCIAMACHY - Mission Objectives and Measurement Modes, J. Atmos. Sci., 56, 125-150, 1999.

Bramstedt, K., Gleason, J., Loyola, D., Thomas, W., Bracher, A., Weber, M., and Burrows, J. P.: Comparison of total ozone from the satellite instruments GOME and TOMS with measurements from the Dobson network 1996-2000, Atmos. Chem. Phys., 3, 1409-1419, 2003,

SRef-ID: 1680-7324/acp/2003-3-1409.

Burrows, J. P., Weber, M., Buchwitz, M., Rozanov, V. V., Ladstädter-Weissenmayer, A., Richter, A., de Beek, R., Hoogen, R., Bramstedt, K., Eichmann, K.-U., Eisinger, M., and Perner, D.: The Global Ozone Monitoring Experiment (GOME): Mission Concept and First Scientific Results, J. Atmos. Sci., 56, 151-175, 1999a.

Burrows, J. P., Richter, A., Dehn, A., Deters, B., Himmelmann, S., Voigt, S., and Orphal, J.: Atmospheric Remote-Sensing Reference Data from GOME: Part 2, Temperature-dependent absorption Cross Sections of $\mathrm{O}_{3}$ in the 231-794 nm range, J. Quant. Spectrosc. Rad. Transfer, 61, 509-517, 1999b.

Coldewey-Egbers, M., Weber, M., Lamsal, L. N., de Beek, R., Buchwitz, M., and Burrows, J. P.: Total ozone retrieval from GOME UV spectral data using the weighting function DOAS approach, Atmos. Chem. Phys., 5, 5015-5025, 2005.

Dobson, G. M. B.: A photo-electric spectrometer for measuring the amount of atmospheric ozone, Proc. Phys. Soc., 324-339, 1931.

Dobson, G. M. B.: Forty year's research on atmospheric ozone at Oxford: a history, Appl. Opt., 7, 387-405, 1968.

Fioletov, V., Kerr, J., Hare, E., Labow, G., and McPeters, R.: An assessment of the world ground-based total ozone network performance from the comparison with satellite data, J. Geophys. Res., 104, 1737-1748, doi:10.1029/1998JD100046, 1999.

GDP V3 VALREPORT, 2002: ERS-2 GOME GDP 3.0 Implementation and Delta Validation Report, Technical Note ERSEDTEX-EOAD-TN-02-0006, Issue 1.0, edited by: Lambert, J.C., November 2002, see also: http://earth.esrin.esa.it/pub/ESA_ DOC/GOME/gdp3/gdp3.htm, 2002.

Gushchin, G. P., Sokolenko, S. A., and Kovalyov, V. A.: Totalozone measuring instruments used at the USSR station network, in Atmospheric Ozone, Proc. Quadr. Ozone Symp., Halkidiki, Greece, 1984, edited by: Zerefos, C. and Ghazi, A., Reidel, Dordrecht, 543-546, 1985. 
Hare, E. and Fioletov, V.: An examination of the total ozone data in the World Ozone and Ultraviolet Radiation Data Center, in: Atmospheric Ozone, Proc. Quadr. Ozone Symp. L'Aquila, Italy, 1996, edited by: Bojkov, R. and Visconti, G., Edigrafital S.p.A.S.Atto (TE), 45-48, 1998.

Herman, J. R. and Celarier, E. A.: Earth surface reflectivity climatology at 340-380 nm from TOMS data, J. Geophys. Res., 102, $28003-28011,1997$.

Kerr, J. B., McElroy, C. T., Wardle, D. I., Olafson, R. A., and Evans, W. P. J.: The automated Brewer Spectrophotometer, in: Atmospheric Ozone, Proc. Quadr. Ozone Symp. Halkidiki, Greece, 1984, edited by: Zerefos, C. and Ghazi, A., Reidel, Dordrecht, 543-546, 1985.

Kerr, J. B., Asbridge, I. A., and Evans, W. F. J.: Intercomparison of total ozone measured by the Brewer and Dobson spectrophotometers at Toronto, J. Geophys. Res., 93, 11 129-11 140, 1988.

Kerr, J., New methodology for deriving total ozone and other atmospheric variables from Brewer spectrometer spectrophotometer direct sun spectra, J. Geophys. Res., 107, doi:10.1029/2001JD001227, 2002.

Koelemeijer, R. B. A., Stammes, P., Hovenier, J. W., and de Haan, J. F.: A fast method for retrieval of cloud parameters using oxygen A-band measurements from the Global Ozone Monitoring Experiment, J. Geophys. Res., 106, 3475-3496, 2001.

Koelemeijer, R. B. A., de Haan, J. F., and Stammes, P.: A database of spectral surface reflectivity in the range $335-772 \mathrm{~nm}$ derived from 5.5 years of GOME observations, J. Geophys. Res., 108, doi:10.1029/2002JD002429, 2003.

Komhyr, W. D., Mateer, C. L., and Hudson, R. D.: Effective BassPaur 1985 ozone absorption coefficients for use with Dobson ozone spectrophotometers, J. Geophys. Res., 98, 20 451-20 465, 1993.

Kurucz, R. L., Furenlid, I., Brault, J., and Testerman, L.: Solar flux atlas from $296 \mathrm{~nm}$ to $1300 \mathrm{~nm}$, National Solar Observatory, Sunspot, New Mexico, 1984.

Laan, E., de Vries, J., Kruizinga, B., Visser, H., Levelt, P., van den Oord, G. H. J., Maelkki, A., Leppelmeier, G., and Hilsenrath, E.: Ozone monitoring with the OMI instrument, in: Proc. of the SPIE's 45th Annual Meeting - The International Symposium on Optical Science and Technology, Vol. 4132-41, 334-343, 2000.
Rozanov, V. V., Kurosu, T., and Burrows, J. P.: Retrieval of Atmospheric Constituents in the UV/visible: A new Analytical Approach to Calculating Weighting Functions, J. Quant. Spectrosc. Rad. Transfer, 60, 277-299, 1998.

Solomon, S., Schmeltekopf, A. L., and Sanders, R. W.: On the interpretation of zenith-sky absorption measurements, J. Geophys. Res., 92, 8311-8319, 1987.

Staehelin, J.: Total ozone series of Arosa (Switzerland), Homogenization and data comparison, J. Geophys. Res., 103, 5827-5841, 1998.

Staehelin, J., Kerr, J., Evans, R., and Vanicek, K.: Comparison of total ozone measurements of Dobson and Brewer spectrophotometers and recommended transfer functions, Tech. Rep., WMO, World Meteorological Organization Global Atmosphere Watch (WMO-GAW) Report 149, 2003.

Tanzi, C. P., Snel, R., Hasekamp, O., and Aben, I.: Degradation of UV earth albedo observations by GOME, in ERS-ENVISAT Symposium, Gothenburg, 16-20 October 2000, ESA Special Publication SP-461 (CD-ROM), 2001.

Vanicek, K.: Differences between Dobson and Brewer observations of total ozone at Hradec-Kralove, in Atmospheric Ozone, Proc. Quadr. Ozone Symp., L'Aquila, 1996, ed. by Bojkov, R., and Visconti, G., 81-84, Edigrafital S.p.A.-S.Atto (TE), 1998.

Vountas, M., Rozanov, V. V., and Burrows, J. P.: Ring Effect: Impact of Rotational Raman Scattering on Radiative Transfer in Earth's Atmosphere, J. Quant. Spectrosc. Radiat. Transfer, 60, 943-961, 1998.

Weber, M., Eichmann, K.-U., Wittrock, F., Bramstedt, K., Hild, L., Richter, A., Burrows, J. P., and Müller, R.: The cold Arctic winter 1995/96 as observed by the Global Ozone Monitoring Experiment GOME and HALOE: Tropospheric wave activity and chemical ozone loss, Quart. J. Roy. Meteorol. Soc., 1293-1319, 2002.

Weber, M., Dhomse, S., Wittrock, F., Richter, A., Sinnhuber, B.-M., and Burrows, J. P.: Dynamical Control of $\mathrm{NH}$ and $\mathrm{SH}$ Winter/Spring Total Ozone from GOME Observations in 1995-2002, Geophys. Res. Lett., 30, 1853-1854, doi:10.1029/2002GL016799, 2003.

Wellemeyer, C. G., Taylor, S. L., Seftor, C. J., McPeters, R. D., and Bhartia, P. K.: A correction for the Total Ozone Mapping Spectrometer profile shape errors at high latitude, J. Geophys. Res., 102, 9029-9038, 1997. 